\title{
Aflatoxin Production by Some Indian Strains of Aspergillus flavus Link ex Fries
}

\author{
By K. K. MAGGON, L. VISWANATHAN, \\ T. A. VENKITASUBRAMANIAN \\ Department of Biochemistry, Vallabhbhai Patel Chest Institute, \\ University of Delhi, Delhi-7, India \\ AND K. G. MUKERJI \\ Department of Botany, University of Delhi, Delhi-7, India
}

(Accepted for publication 13 August 1969)

SUMMARY

Nine strains of Aspergillus flavus and one each of A. versicolor, A. penicilliformis and $A$. niger isolated from Delhi soils were screened for ability to produce aflatoxins on different media. Seven strains of $A$. flavus produced aflatoxins $B_{1}$ and $B_{2}$ but no aflatoxin $G$. The other five isolates produced no detectable aflatoxins. Yields of aflatoxins were low on glucose-salts or sucrose-yeast extract media. The latter with added salts or a modified Czapek agar medium gave enhanced yields.

\section{INTRODUCTION}

Aspergillus flavus infects a wide variety of foods, especially groundnut during storage and produces a group of compounds called aflatoxins. These are highly toxic and also carcinogenic to a number of avian and mammalian species (Wogan, I966; Schoental, 1967).

A review of the recent literature reveals that the production of aflatoxin is limited to some strains of Aspergillus flavus and A. parasiticus. Earlier reports (Mateles \& Wogan, 1967) of formation of aflatoxins by other Aspergillus species and by Penicillium have not been confirmed (Wilson, Campbell, Hayes \& Hanlin, I968; Mislivec, Hunter \& Tuite, I968).

Several Aspergillus isolates have been screened by different groups of workers for toxin production (Kulik \& Holaday, I966; Parrish, Wiley, Simmons \& Long, I966; Murakami, Takase \& Ishii, I967; Van Walbeek, Scott \& Thatcher, I968). Only limited information on the toxin-producing ability of Indian strains of Aspergillus flavus is available. This paper presents data on the formation of aflatoxins in different kinds of media by strains of A. flavus isolated from the soils of Delhi.

\section{METHODS}

Isolation of fungi. Soil samples were collected under sterile conditions from the agricultural farm of Delhi University, situated near the village Dhaka. Aspergilli were isolated by the dilution plate method of Waksman (I922) either immediately on arrival at the laboratory or after storage at $8^{\circ}$. Nine strains of Aspergillus flavus 
Link were isolated and they were selected for the present investigations. Three other species, Aspergillus versicolor (Vuillemin) Tiraboshi (DU/KR 84), A. niger van Tieghem (DU/KR 85) and $A$. penicilliformis Kamyscho (DU/KR 29), isolated from soil samples collected from the same locality have also been included in these studies.

Characters of isolates of Aspergillus flavus Link ex Fries. Colonies on modified Czapek agar were fast growing. Strains DU/KR 79-A, C, D, E and G had white mycelia. Strains DU/KR 79-A and $\mathrm{C}$ formed also a small number of dark brown sclerotia. In $\mathrm{DU} / \mathrm{KR} 79-\mathrm{B}$ and $\mathrm{H}$ the mycelium was fluffy, while DU/KR 79-F and $\mathrm{K}$ had a yellowish mycelium. In all the strains, the surface of the colony was crinkled and greyish-green spores were formed near the edges of the colony (Raper \& Fennell, I965).

On a $2 \%$ glucose, $2 \%$ peptone medium, DU/KR 79-A, C, D, E and G strains of Aspergillus flavus produced abundant sporulation and small brown to pinkish sclerotia. Strain DU/KR 79-F formed bigger straw to light brown sclerotia. Isolates DU/KR 79-B, $\mathrm{K}$ and $\mathrm{H}$ were purely conidial strains and did not produce any sclerotia.

Maintenance and growth. The strains were maintained on slants of modified Czapek agar (below) in the cold and subcultured monthly. For tests of toxin production cultures were transferred to bottles containing $50 \mathrm{ml}$. agar medium. After I to 2 weeks, spores were transferred to $100 \mathrm{ml}$. liquid medium in a $500 \mathrm{ml}$. Erlenmeyer flask and incubated at $25 \pm \mathrm{I}^{\circ}$ for 7 days. In some cases, instead of transferring to a liquid medium, the agar cultures were directly extracted with chloroform.

Modified Czapek agar medium (Davis, Diener \& Eldridge, I966). Difco yeast extract, 7 g.; sucrose, 200 g.; $\mathrm{NaNO}_{3}, 3$ g.; $\mathrm{K}_{2} \mathrm{HPO}_{4}$, I g.; $\mathrm{KCl}, 0.5$ g.; $\mathrm{FeSO}_{4} .7 \mathrm{H}_{2} \mathrm{O}$, o.o I g.; $\mathrm{MgSO}_{4} \cdot 7 \mathrm{H}_{2} \mathrm{O}, 0.5 \mathrm{~g}$.; agar, 20 g.; distilled water, I 1.; pH 6.4.

$2 \%$ YES medium (Davis et al. 1966). Difco yeast extract, $20 \mathrm{~g}$; ; sucrose, $200 \mathrm{~g}$; distilled water, 11 .; $\mathrm{pH} 6 \cdot 4$.

$0.7 \%$ YES + salts medium. Difco yeast extract, $7 \mathrm{~g}$.; sucrose, $200 \mathrm{~g} . ; \mathrm{NaNO}_{3}, 3 \mathrm{~g}$.; $\mathrm{KH}_{2} \mathrm{PO}_{4}$, I g.; $\mathrm{KCl}, 0.5 \mathrm{~g}$.; $\mathrm{FeSO}_{4} .7 \mathrm{H}_{2} \mathrm{O}, 0.0 \mathrm{I}$ g. ; $\mathrm{MgSO}_{4} .7 \mathrm{H}_{2} \mathrm{O}$, 0.5 g.; distilled water, 11 .; $\mathrm{pH} \mathrm{6.0.}$

GAN medium (Brian et al. I96I). Glucose, 60 g.; $\mathrm{NH}_{4} \mathrm{NO}_{3}, 2 \cdot 4 \mathrm{~g}$.; $\mathrm{KH}_{2} \mathrm{PO}_{4}$, I0.0 g.; $\mathrm{MgSO}_{4} \cdot 7 \mathrm{H}_{2} \mathrm{O}, 2 \cdot 0 \mathrm{~g}$.; $\mathrm{ZnSO}_{4} \cdot 7 \mathrm{H}_{2} \mathrm{O}, 26 \cdot 6 \mathrm{mg}$.; $\mathrm{CuSO}_{4} \cdot 5 \mathrm{H}_{2} \mathrm{O}, 2.67 \mathrm{mg}$.; $\mathrm{Co}\left(\mathrm{NO}_{3}\right)_{2}$. $6 \mathrm{H}_{2} \mathrm{O}, \mathrm{I} \cdot 36 \mathrm{mg}$.; $\mathrm{CaCl}_{2}, 66.67 \mathrm{mg}$.; distilled water, I l; $\mathrm{pH} 6 \cdot 0$.

To observe the effect of groundnut, $2 \%$ of powdered groundnut cake from which most of the oil had been removed by pressing was added to the last two media.

Extraction of cultures. After 7 days growth, agar cultures were washed once with distilled water, $100 \mathrm{ml}$. distilled water was added and agar was melted. The contents were then extracted twice with $200 \mathrm{ml}$. chloroform.

At the end of the incubation period, mycelium was separated from liquid media, washed twice with distilled water, blotted well and its wet weight determined. It was then extracted by grinding with sand and chloroform in a glass mortar; the separated medium was extracted thrice with $100 \mathrm{ml}$. chloroform. Extracts were dried over anhydrous sodium sulphate, evaporated under reduced pressure in a rotary film evaporator and made up to a known volume.

Estimation of aflatoxins. 100 to $200 \mu \mathrm{l}$. of chloroform extract were applied to plates coated with $250 \mu$ thick silica gel G (E. Merck) which had been activated at $110^{\circ}$ for $\mathrm{I}$ hr. The plates were developed in methanol + chloroform $(2+98, \mathrm{v} / \mathrm{v})$. Aflatoxin $\mathrm{B}$ bands were located with an ultraviolet lamp, scraped out and eluted thrice with $3 \mathrm{ml}$. methanol (BDH, AR). The eluates were made up to $10 \mathrm{ml}$. and aflatoxins were deter- 
mined by measuring the o.d. at $363 \mathrm{~m} \mu$ on a Beckman model DU Spectrophotometer and using the extinction coefficients reported by Nabney \& Nesbitt (I965).

The ultraviolet and infrared spectra of the extracts were determined on a Beckman model DU and a Perkin Elmer Model 137 Infracord Spectrometer respectively and compared with authentic aflatoxin B formed by Aspergillus flavus ATCC I55I7. Toxicity was also checked by injecting propylene glycol solutions of the t.l.c. eluates into I-day-old chickens at $6 \mathrm{mg}$. $/ \mathrm{kg}$. body wt.

\section{RESULTS AND DISCUSSION}

Five strains of Aspergillus flavus formed large amounts of aflatoxin, two gave small amounts, while the other two formed none. One strain each of Aspergillus versicolor, $A$. niger and $A$. penicilliformis produced no aflatoxin on any of the media used (Table I).

The toxin-producing strains formed only aflatoxins $B_{1}$ and $B_{2}$. Aflatoxin $B_{1}$ on from these strains was identical with authentic aflatoxin $B_{1}$ in thin-layer chromatographic behaviour, infrared and ultraviolet spectra and biological activity.

\section{Table I. Aflatoxin formation by Aspergillus strains}

Amounts of aflatoxin $\mathbf{B}_{\mathbf{1}}$ plus $\mathbf{B}_{\mathbf{2}}$ formed on $50 \mathrm{ml}$. modified Czapek agar medium in 7 days at $25^{\circ}$ are expressed as the average of two sets of experiments.

$\begin{array}{clc}\text { Strain } & \text { Species } & \begin{array}{c}\text { Aflatoxins B formed } \\ \text { (mg.) }\end{array} \\ \text { DU/KR 79 A } & \text { A. flavus } & 16.88 \\ \text { DU/KR 79 C } & \text { A. flavus } & 18.73 \\ \text { DU/KR 79 D } & \text { A. flavus } & 18.76 \\ \text { DU/KR 79 E } & \text { A. flavus } & 13.35 \\ \text { DU/KR 79 F } & \text { A. flavus } & \mathrm{I} \cdot 46 \\ \text { DU/KR 79 G } & \text { A. flavus } & \mathrm{I} 9.5 \mathrm{I} \\ \text { DU/KR 79 K } & \text { A. flavus } & 0.64 \\ \text { ATCC 155I7 } & \text { A. flavus } & \mathrm{I} \cdot 40\end{array}$

A. flavus DU/KR 79 B, A. flavus DU/KR 79 H, A. versicolor DU/KR 84, A. penicilliformis DU/KR 29 (IMI I 32430), A. niger DU/KR 85 formed none.

It is remarkable that all the seven strains isolated from soil form only aflatoxins $B_{1}$ and $B_{2}$. In a typical estimation, the amount of $B_{2}$ was about $I \cdot 5 \%$, the rest being aflatoxin $\mathrm{B}_{1}$. Most of the strains of Aspergillus flavus reported in the literature produce aflatoxins B and $\mathrm{G}$. Some strains have been reported to form only aflatoxin B on certain media (Schroeder \& Ashworth, I966). Van Walbeek et al. (1968) have described strains of $A$. flavus var. columnaris which produce only aflatoxin $\mathrm{B}_{2}$. All the isolates reported in this study yielded only aflatoxins $B_{1}$ and $B_{2}$ and not $G$, in all the media tested.

The GAN medium has been recommended for high toxin production (Raper \& Fennell, 1965). The strains studied here gave comparatively low yields on this medium (Table 2). Davis et al. (I966) reported very high levels of aflatoxin production on a $2 \%$ YES medium and claimed as much as $63 \mathrm{mg}$./ $100 \mathrm{ml}$. medium with certain strains. This medium gave lower yields than GAN medium in the present study.

As the modified Czapek agar medium supported the production of large amounts of aflatoxin, a liquid medium having the same composition but without agar was tested and gave good yields (Table 3). Omission of the salts from this medium led to 
a large decrease in the amount of toxins produced, indicating that the salts are in some way essential for toxin formation. On the other hand, addition of these salts to YES medium markedly decreased toxin production by $A$. flavus ATCC I55 77 .

The Aspergillus flavus strains studied by Davis et al. (1966) also did not need the salts for toxin production. These facts indicate the importance of trace elements and also show that their effect may vary from strain to strain.

\section{Table 2. Production of aflatoxin B by Aspergillus flavus strains in a glucose-salts medium}

Amounts of aflatoxin $B_{1}$ plus $B_{2}$ formed in $100 \mathrm{ml}$. stationary cultures in 7 days at $25^{\circ}$ are expressed as averages of two sets of experiments.

\begin{tabular}{|c|c|c|c|c|c|c|c|c|}
\hline \multirow[b]{3}{*}{ Strain } & \multicolumn{4}{|c|}{ GAN medium } & \multicolumn{4}{|c|}{ GAN $+2 \%$ groundnut medium } \\
\hline & \multirow{2}{*}{$\begin{array}{l}\text { Mycelial } \\
\text { wet wt } \\
\text { (g.) }\end{array}$} & \multicolumn{3}{|c|}{ Aflatoxin B formed (mg.) } & \multirow{2}{*}{$\begin{array}{l}\text { Mycelial } \\
\text { wet wt } \\
\text { (g.) }\end{array}$} & \multicolumn{3}{|c|}{ Aflatoxin B formed (mg.) } \\
\hline & & Mycelium & Medium & Total & & Mycelium & Medium & Total \\
\hline $\mathrm{DU} / \mathrm{KR} 79 \mathrm{~A}$ & $5 \cdot 04$ & 0.69 & 0.83 & $1 \cdot 52$ & 10.42 & $I \cdot 29$ & 0.52 & $\mathbf{I} \cdot 8 \mathrm{I}$ \\
\hline $\mathrm{DU} / \mathrm{KR} 79 \mathrm{C}$ & $6 \cdot 25$ & 0.58 & 0.93 & $1 \cdot 51$ & $10 \cdot 60$ & $1 \cdot 40$ & 0.73 & $2 \cdot 13$ \\
\hline DU/KR $79 \mathrm{D}$ & 5.04 & $I \cdot 00$ & $1 \cdot 51$ & $2 \cdot 5 \mathrm{I}$ & 10.02 & $2 \cdot 00$ & 0.87 & 2.87 \\
\hline DU/KR $79 \mathrm{E}$ & $5 \cdot 60$ & 0.07 & $0 \cdot 13$ & $0 \cdot 20$ & $9 \cdot 21$ & Trace & Trace & Trace \\
\hline DU/KR $79 \mathrm{~F}$ & $5 \cdot 25$ & 0.04 & Trace & 0.04 & 10.25 & 0.44 & 0.24 & 0.68 \\
\hline DU/KR $79 \mathrm{G}$ & $5 \cdot 50$ & 0.80 & $I \cdot 09$ & $1 \cdot 89$ & $9 \cdot 13$ & 0.80 & 0.70 & $I \cdot 50$ \\
\hline U/KR $79 \mathrm{~K}$ & 5.40 & Trace & Trace & Trace & $8 \cdot 45$ & 0.05 & Trace & 0.05 \\
\hline
\end{tabular}

Table 3. Production of aflatoxin B by Aspergillus flavus strains in sucrose-yeast extract media

Amounts of aflatoxin $B_{1}$ plus $B_{2}$ formed in $100 \mathrm{ml}$. stationary cultures in 7 days at $25^{\circ}$ are expressed as averages of two sets of experiments.

\begin{tabular}{|c|c|c|c|c|c|c|c|c|c|}
\hline \multirow[b]{3}{*}{ Strain } & \multirow{3}{*}{$\begin{array}{c}2 \% \text { YES } \\
\text { medium } \\
\text { Total } \\
\text { mg. of } \\
\text { aflatoxins } \\
\text { B formed }\end{array}$} & \multicolumn{4}{|c|}{$0.7 \%$ YES + salts medium } & \multicolumn{4}{|c|}{$0.7 \%$ YES + salts $+2 \%$ groundnut mediu } \\
\hline & & \multirow{2}{*}{$\begin{array}{c}\text { Mycelial } \\
\text { wet wt } \\
\text { (g.) }\end{array}$} & \multicolumn{3}{|c|}{ Aflatoxin B formed (mg.) } & \multirow{2}{*}{$\begin{array}{c}\text { Mycelial } \\
\text { wet wt } \\
\text { (g.) }\end{array}$} & \multicolumn{3}{|c|}{ Aflatoxin B formed (mg.) } \\
\hline & & & Mycelium & Medium & Total & & Mycelium & Medium & Total \\
\hline DU/KR $79 \mathrm{~A}$ & 0.35 & $9 \cdot 90$ & $\mathrm{I} \cdot 53$ & $5 \cdot 97$ & $7 \cdot 50$ & $9 \cdot 60$ & $2 \cdot 16$ & $2 \cdot 87$ & 5.03 \\
\hline DU/KR $79 \mathrm{C}$ & 0.35 & 6.90 & $2 \cdot 06$ & $7 \cdot 10$ & $9 \cdot 16$ & 10.47 & $\mathrm{I} \cdot 00$ & $2 \cdot 25$ & $3 \cdot 25$ \\
\hline DU/KR 79 D & 0.53 & $8 \cdot 20$ & $3 \cdot 37$ & $9 \cdot 70$ & 13.07 & $7 \cdot 75$ & $2 \cdot 52$ & $3 \cdot 40$ & $5 \cdot 92$ \\
\hline DU/KR $79 \mathrm{E}$ & 0.18 & $8 \cdot 22$ & I. 46 & $4 \cdot 89$ & $6 \cdot 35$ & $9 \cdot 85$ & $4 \cdot 00$ & $2 \cdot 85$ & $6 \cdot 85$ \\
\hline DU/KR $79 \mathrm{~F}$ & 0.12 & $5 \cdot 94$ & 0.25 & $1 \cdot 60$ & $\mathrm{I} \cdot 85$ & 10.71 & 0.48 & $\mathrm{I} \cdot \mathrm{I} 5$ & $1 \cdot 63$ \\
\hline $\mathrm{DU} / \mathrm{KR} 79 \mathrm{G}$ & 0.17 & $7 \cdot 88$ & 2.65 & 10.08 & $12 \cdot 73$ & $9 \cdot 10$ & $3 \cdot 43$ & 4.59 & 8.02 \\
\hline DU/KR $79 \mathrm{~K}$ & Trace & $7 \cdot 55$ & 0.14 & 0.22 & 0.36 & $12 \cdot 30$ & $0 \cdot 16$ & 0.20 & 0.36 \\
\hline
\end{tabular}

Effects of addition of groundnut. Schroeder (1966) and Davis et al. (1966) reported that the yield of aflatoxins decreases after repeated subculture in media devoid of crude natural materials and also that the yield in synthetic media increases on addition of natural products such as cornsteep liquor or yeast extract. Recent work in this laboratory with Aspergillus flavus ATCC I5517 showed that repeated subcultures in agar media containing groundnut increased the organism's ability to produce aflatoxins on YES medium. Evidence has also been obtained for the presence of both stimulatory and inhibitory factors in groundnut. Therefore the effect of adding groundnut to the $0.7 \%$ YES plus salts medium and GAN medium was studied. The results obtained varied with the medium and the strain used. 
In GAN medium, more aflatoxin was usually produced with groundnut. There was a tendency for the aflatoxin content of medium to decrease and that of mycelium to increase (Table 2). In YES medium, the total aflatoxin generally decreased: aflatoxin in medium decreased while a variable effect was observed on aflatoxin in the mycelium. The effect of different media on aflatoxin production did not necessarily depend on their effect on growth as Tables 2 and 3 illustrate.

Of the isolates studied here, only strains of Aspergillus flavus with sclerotia produced aflatoxins. Surprisingly, the non-sclerotial strains (DU/KR 79-B, K and $\mathrm{H}$ ) produced very little of these compounds. This may to some extent be due to heterokaryosis (Pontecorvo, 1947), which means the association of genetically unlike haploid nuclei in a mycelium due to hyphal anastomosis. The production of different types of aflatoxins such as B and G may be controlled by different haploid nuclei; presence or absence of these may affect the fungal metabolism.

The fact that these strains produce only aflatoxin B and the apparent marked effect of trace elements on toxin production may help in studies on the mode of formation of aflatoxins. These strains can be used for the preparation of afiatoxin $B$ uncontaminated by aflatoxin $\mathrm{G}$, especially in view of the good yields obtained on modified Czapek agar medium.

This investigation was financed by a PL-480 grant No. FG-In-259. Our thanks are due to Dr V. N. Damodaran and Dr S. Abraham of the Pathology Department of our Institute for examining liver sections from chicken injected with fungal extracts. Dr R. Shankaran has helped in the biological testing of the aflatoxins in chicken.

\section{REFERENCES}

Brian, P. W., Dawkins, A. W., Grove, J. F., Hemming, H. G., Lowe, D. \& Norris, G. L. F. (I96I). Phytotoxic compounds produced by Fusarium equiseti. J. exp. Bot. 12, I.

Davis, N. D., Diener, U. L. \& Eldridge, D. W. (1966). Production of aflatoxin $B_{1}$ and $G_{1}$ by Aspergillus flavus in a semisynthetic medium. Appl. Microbiol. 14, 378.

Kulik, M. M. \& Holaday, C. E. (I966). Aflatoxin: a metabolic product of several fungi. Mycopath. Mycol. appl. 30, 137.

Mateles, R. I. \& Wogan, G. N. (I967). Aflatoxin. In Advances in Microbial Physiology. Ed. by A. H. Rose and J. F. Wilkinson, vol. I, p. 25. New York: Academic Press.

Mislivec, P. B., Hunter, J. H. \& Tuite, J. (I968). Assay for aflatoxin production by the genera Aspergillus and Penicillium. Appl. Microbiol. 16, 1053.

Murakami, H., TAKase, S. \& IshII, T. (1967). Non-productivity of aflatoxin by Japanese industrial strains of Aspergillus. I. Production of fluorescent substances in agar slant and shaking cultures. J. gen. appl. Microbiol., Tokyo 13, 323.

NABNEY, J. \& NeSBITT, B. F. (I965). A spectrophotometric method for determining the aflatoxins. Analyst, Lond. 90, 155.

Parrish, F. W., Wiley, B. J., Simmons, E. G. \& Long, L. Jun. (1966). Production of aflatoxins and kojic acid by species of Aspergillus and Penicillium. Appl. Microbiol. 14, 139.

Pontecorvo, G. (1947). Genetic systems based on heterokaryosis. Cold Spring Harb. Symp. quant. Biol. II, 193.

RaPer, K. B. \& Fennell, D. I. (1965). The Genus Aspergillus. Baltimore, Md., U.S.A.: The Williams and Wilkins Company.

Schoental, R. (1967). Aflatoxins. A. Rev. Pharmac. 7, 343.

SCHROEDER, H. W. (I966). Effect of corn steep liquor on mycelial growth and aflatoxin production in Aspergillus parasiticus. Appl. Microbiol. 14, 381. 
SChroeder, H. W. \& Ashworth, Jun, L. J. (1966). Aflatoxins. Some factors affecting production and location of toxins in Aspergillus flavus-oryzae. J. Stored Prod. Res. 1, 267.

van Walbeek, W., Scott, P. M. \& Thatcher, F. S. (I968). Mycotoxins from food-borne fungi. Can. J. Microbiol. I4, $13 \mathrm{I}$.

WAKSMAN, S. A. (1922). A method for counting the number of fungi in the soil. J. Bact. 7, 339.

Wilson, B. J., Campbell, T. C., Hayes, A. W. \& Hanlin, R. T. (1968). Investigation of reported aflatoxin production by fungi outside the Aspergillus favus group. Appl. Microbiol. r6, 819. Wogan, G. N. (I966). Chemical nature and biological effects of the aflatoxins. Bact. Rev. 30, 460. 